\title{
Industrial Engineering Beyond Numbers: Optimizing under Ethics
}

\section{Dr. Alejandro Salado, Virginia Tech}

Dr. Alejandro Salado is an assistant professor of systems science and systems engineering with the Grado Department of Industrial \& Systems Engineering at Virginia Tech. His research focuses on unveiling the scientific foundations of systems engineering and using them to improve systems engineering practice. Before joining academia, Alejandro spent over ten years as a systems engineer in the space industry. $\mathrm{He}$ is a recipient of the Fabrycky-Blanchard Award for Systems Engineering Research and the Fulbright International Science and Technology Award. Dr. Salado holds a BSc/MSc in electrical engineering from Polytechnic University of Valencia, an MSc in project management and a MSc in electronics engineering from Polytechnic University of Catalonia, the SpaceTech MEng in space systems engineering from Delft University of Technology, and a $\mathrm{PhD}$ in systems engineering from the Stevens Institute of Technology. $\mathrm{He}$ is a member of INCOSE and a senior member of IEEE and IIE. 


\title{
Industrial Engineering beyond Numbers: Optimizing under Ethics
}

\begin{abstract}
Optimization is a major component of industrial engineering. Simplistically (and naively), the education of industrial engineers focuses on learning a number of techniques with which they can mathematically model a number of scenarios and optimize a mathematical function that is subjected to various mathematical constraints. Reality works differently though. The implementation of optimization actions in a real context yields direct and indirect impacts to society and to individual people. They are further strengthened when projects are implemented or executed in international settings, where different systems of laws, regulations, cultures, and values play a role. Several examples in the past have shown dramatic consequences for not considering ethical implications of engineering decisions in real projects. Therefore, exposing students to ethical conflicts, as well as educating them in the skills, competences, and tools necessary to cope with them, are necessary in the education of every engineer. This paper highlights the integration of ethics into an existing, traditional industrial engineering undergraduate course at the senior level. In particular, we show how traditional optimization assignments can be reformulated to blend mathematics and ethics. Therefore, we do not follow the path of developing an independent, elective course that focuses on ethical issues.

Furthermore, integration of ethics is not performed through case studies on which students can reflect on their own experiences. Instead, we embed ethical issues in traditional industrial engineering knowledge. In this way, ethical conflicts reveal themselves to students as students attempt to solve a traditional industrial engineering assignment. In this way, students are exposed to an ethical conflict with no baseline course of action, but they need to find alternatives and choose their own course of action without any prior or existing information about potential outcomes and impacts of their decisions. While traditional industrial engineering techniques and tools help in informing the decision, students realize that they are not sufficient to provide an answer to the problem by themselves. Personal decision-making is necessary. Answers to assignments are then shared and discussed in class with the objectives of understanding, accepting, and embracing solution diversity as a function of personal ethics. This is key for students to understand that there are not "by the book" answers to resolving ethical conflicts, but that solutions reduce in several cases to personal ethics. Finally, students also learn about the ability and obligation of an engineer to use "no" as a valid and professional engineering solution, which can be used when there is a conflict between an engineering assignment, its solution, its recommendations, and personal ethics.
\end{abstract}

\section{The need for incorporating ethics in engineering curricula}

In this paper, ethics is understood as a system of ethical principles and values that guide each individual's actions, some of which may be informed by engineering codes of ethics. An ethical conflict in this context may arise when an individual may decide for an alternative that is not aligned with those ethical principles and values.

A formal justification for the need to incorporate ethics in engineering curricula can be made by referencing $\mathrm{ABET}$, which requires "an understanding of professional and ethical responsibility, 
broad education necessary to understand the impact of engineering solutions in a global and societal context" (ABET, 2007, p. 1). Informally, two examples can set the ground.

Example 1: Challenger. In 1986, the Space Shuttle Challenger disintegrated during launch, instantly killing its crew. Assessment of failure root cause, led to concluding that launch was approved despite the predicted operating temperature for one of its components (the O-ring) was going to be -3 degree $\mathrm{C}$, below the temperature range at which the component had been tested (4 degree C). Political pressures for the program led to decision makers to ask, "Do you know that it will fail for sure?" instead of "Are we sure it will work?" For the launch to be approved a number of engineers signed their consent to the launch, when there was no engineering evidence that it was safe to conduct the launch.

Example 2: Dieselgate. A scandal arose in 2015, when the United States Environmental Protection Agency found that Wolkswagen had programmed some its vehicles to activate certain emission control mechanisms only during testing, in order to obtain the necessary certifications, although during their regular operations they would emit well beyond the established limits. Again in this case, this situation was made possible because a number of engineers signed their consent to this design features.

Although these examples lay at the extreme of negative consequences stemming from not adequately resolving ethical issues, the professional practice of engineering is plagued by small ethical conflicts that engineers face: interpretation of test results, deciding on whether use analyses or tests to support a given decision, or deciding on how representative an element under test is with respect to its envisaged usage. In general, engineers need to balance in these decisions their personal engineering judgement with the demands and needs of their employers. The following story from the author's personal experience, who spent over 10 years in the space industry as a practicing engineer before joining academia, is illustrative:

As the development of a satellite was ending, we (team members) started to talk to each other about what was coming next for us. One of my colleagues said that he was planning to write the continuation of Harry Potter. Intrigued by the idea, we asked him why. His answer was enlightening: "I have had to write so much science fiction in this project, that I feel totally capable to do it!"

Engineering work affects society. Consequently, engineers have an inherent responsibility as part of their engineering practice for public safety and environmental sustainability, which requires engineers to practice engineering honestly and fairly (Colby \& Sullivan, 2008). As a result, multiple efforts in engineering education are geared towards incorporating ethics concepts in engineering curricula. Some of these efforts are described in the next section. In fact, some authors suggest that ethics should be made a cornerstone element in engineering education (Moore, 2011). However, this has not been achieved yet and students lack the necessary exposure during their education to navigate through the ethical conflicts they will face during their careers (Herkert, 2002).

This paper contributes to this body of work by blending ethics with traditional optimization problems in industrial engineering. The proposed approach enables incorporating ethics without 
increasing or modifying existing curricula, fosters active learning, and exposes students to feel the ethical dilemmas when resolving them.

\section{Previous efforts to incorporate ethics concepts into engineering curricula}

Engineering education makes use of three basic approaches to incorporate ethics to engineering curricula: (1) stand-alone courses in ethics, e.g. (Herkert \& Viscomi, 1991), (2) modules of engineering ethics in engineering courses, e.g. (Alenskis, 1997), and (3) discussions, case studies, and homework exercises where students are exposed to perform "trade-off's between potentially conflicting values such as cost and safety" (Colby \& Sullivan, 2008).

Because students are not particularly interested in ethics, they tend to avoid taking stand-alone courses in ethics (Herkert, 1999). In fact, discussion of well-known cases seem to the central pedagogy for engineering ethics (Colby \& Sullivan, 2008). However, this approach presents limitations because they do not "require students to struggle with the trade-offs involved in actual engineering decisions or with the fact that the consequences of those decisions become clear only in retrospect" (Colby \& Sullivan, 2008). Presenting students with "tradeoffs between potentially conflicting values such as cost and safety" (Colby \& Sullivan, 2008) seems then a promising alternative. However, such tradeoffs only require the elicitation of the student's system of ethical values and principles to come up with his/her own value function. Techniques to perform this activity, which thus include elicitation of personal preferences, have been described (Clemen \& Reilly, 2004; Hazelrigg, 1998, 1999). Hence, the student does not actually need to resolve an ethical conflict, but just understand his/her own values. Other approaches include use of engineering codes as a framework to teaching ethics (Colby \& Sullivan, 2008) or developing ethics as part of co-ops programs (Fleischmann, 2004). The latter demands an additional effort of students beyond their engineering curriculum. The former is limited to describe where ethical issues may arise, but does not provide an operationalized approach to carry out the activity. Hence, integrating ethics with other learning goals and using active pedagogies seem a promising path to successful ethics education in engineering (Colby \& Sullivan, 2008).

Micro-insertions have been proposed as an approach that fulfills both criteria (Davis \& Riley, 2008). In micro-insertions, traditional problems are reformulated to include ethics elements. In particular, the context of the problem is changed so that a student solves the problem to provide a recommendation as an employee, instead of as an engineer only (Davis \& Riley, 2008). This idea, which is central to this paper, places the student in scenarios with potential misalignments between the preferred technical solution and the solution that may be more convenient to his/her company. In this paper, we push the idea further. Specifically, we incorporate misalignments between corporate's preferences and the student's system of ethical values and principles, as well as the student's system of ethical values and principles and his/her own individual system of preferences as an employee of a company that may not want to lose his/her job.

Finally, literature suggests that assessment poses a threat on the effectiveness of integrating ethics with other learning goals (Colby \& Sullivan, 2008). Specifically, allocation of a minor part of the grade to the ethics component, provide an unconscious indication to students of the importance that is given to the ethics in contrast with the importance that is given to mathematics 
(Colby \& Sullivan, 2008). In order to mitigate this threat, we propose in this paper a rubric that provides ethics the necessary importance without diminishing the importance of other traditionally engineering learning goals.

\section{Proposed approach: Blending mathematics and ethics in traditional Industrial Engineering (IE) courses}

\section{Description}

This paper proposes to integrate ethics in traditional optimization problems. Essentially, traditional assignments are slightly modified in such a way that ethical conflicts emerge when the assignments are being solved.

The purpose of the assignments is threefold:

1) Students still acquire the traditional industrial engineering competence that is sought, e.g. learning how to perform an optimization method, or how to allocate facilities.

2) Students need to make a decision where their individual system of ethical principles and values play a role, that is, students need to feel the conflict and actively solve it.

3) Students learn that opting out is a valid answer to the problem.

This allows for seamlessly integrating ethics in engineering curricula without increasing its already loaded effort. At the same time, it also fosters active learning; it is the student who has to face an unprecedented ethical conflict and make a personal call about how to resolve it.

Table 1 shows an example of how a traditional facility location problem can be modified to incorporate ethics. The modified part of the assignment is in italics.

Table 1. Proposed assignments that incorporate ethics in traditional optimization assignments

\begin{tabular}{|l|l|}
\hline \multicolumn{1}{|c|}{ Traditional assignment } & \multicolumn{1}{c|}{ Proposed assignment } \\
\hline You are tasked to define the location for a & Your boss tasks you to define the location for \\
new manufacturing facility for your company. & a new manufacturing facility for your \\
You are offered three alternative locations: A, & company. You are offered three alternative \\
B, and C, with economic conditions X, Y, and & locations: A, B, and C, with economic \\
Z, respectively. Using & conditions X, Y, and Z, respectively. Please, \\
Break-even analysis, please choose the & note that child labor is legal in location A; \\
preferred location. & employees in location B are forced to work 18 \\
& $\begin{array}{l}\text { hours/day; and location } \text { C throws } \\
\text { contaminants resulting from the }\end{array}$ \\
& $\begin{array}{l}\text { manufacturing processes to the ocean. Using } \\
\text { Break-even analysis, please choose the } \\
\text { preferred location. }\end{array}$ \\
\hline
\end{tabular}

In the traditional assignment, a student would compute the resulting economic performance for each location and choose the one optimizing the requested evaluation metric. The selection of the best alternative is a direct reaction to the mathematical exercise. In the proposed assignment, the same effort needs to be made to start. However, the notion of best alternative changes because of 
the non-economic conditions associated to the assignment. Specifically, these conditions are designed to make the student face an ethical conflict that needs to be resolved before leaning towards a specific alternative.

Specifically, incorporating contextual information makes the student's system of ethical values and principles confront his/her personal benefit, which results from promoting the success of his/her employer or his/her profession. The personalization on the student as the decision-maker in this situation actually expands the evaluation of the conflict beyond the right/wrong confrontation. In the proposed example, a student does not only need to evaluate the rightness or wrongness of the contextual information of each alternative (according to his/her individual system of preferences), but also how to balance their evaluation with their individual need to satisfy their employer and maintain their job. In other words, while previous efforts have focused on resolving trade-offs that need to allocate priorities to various properties, such as cost and safety, the uniqueness of this approach is that the actual confrontation emerges between (a) adhering to my personal benefit by recommending something that aligns with the corporate value system (thus, guaranteeing my job), or instead (b) adhering to my individual value system by recommending something that may not align with the corporate value system (thus, threatening my job).

In addition, splitting the assignment's mathematical result from the choice creates a new opportunity for the student: the ability to opt-out from the choice; the ability to say 'No'. Traditionally, students are expected to provide definitive answers to assignments in engineering education, since current assignments do not distinguish between result and choice. It is my personal belief that sustaining this behavior during four or more years of education actually leads practicing engineers to be unable to delink these two elements in actual projects. However, engineers should have the empowerment (and power) to leave documents unsigned, that is, to do not recommend any particular course of action if all alternatives conflict with their own system of ethical principles and values, or even professional standards of quality.

Hence, multiple solutions are possible to this assignment. Figure 1 shows a taxonomy of the types of solutions that are anticipated. Table 2 provides a list of learning impacts associated to the various types of solutions. The taxonomy is constructed as follows. When solving the assignment, students can either consider the non-economic contextual conditions or not. If they do not consider them, then their solution will be completely aligned with the company's preferences (this would be like solving a traditional assignment). If the contextual conditions are considered, they can be either irrelevant to the student's system of preferences or relevant. If irrelevant, then there is no ethical conflict emerging and thus the solution would align with company's preferences. If relevant, the various non-economic conditions can either have equal value in the student's system of preferences or have different value. If they have equal value, then the student has two options: go with the solution that benefits the company or opt out of the decision. If there are differences in value, then either the ranking order of the alternative according to company's preferences is the same as the order generated by the student's system, or preferences, or the orders are not the same. If the orders are aligned, then a student may either choose a solution according to their value and the company's preferences, or opt out of the decision. If the orders are not aligned, then a student may choose the alternative that aligns with 
company's preferences, the solution that aligns with his/her system of preferences, or opt out of the decision.

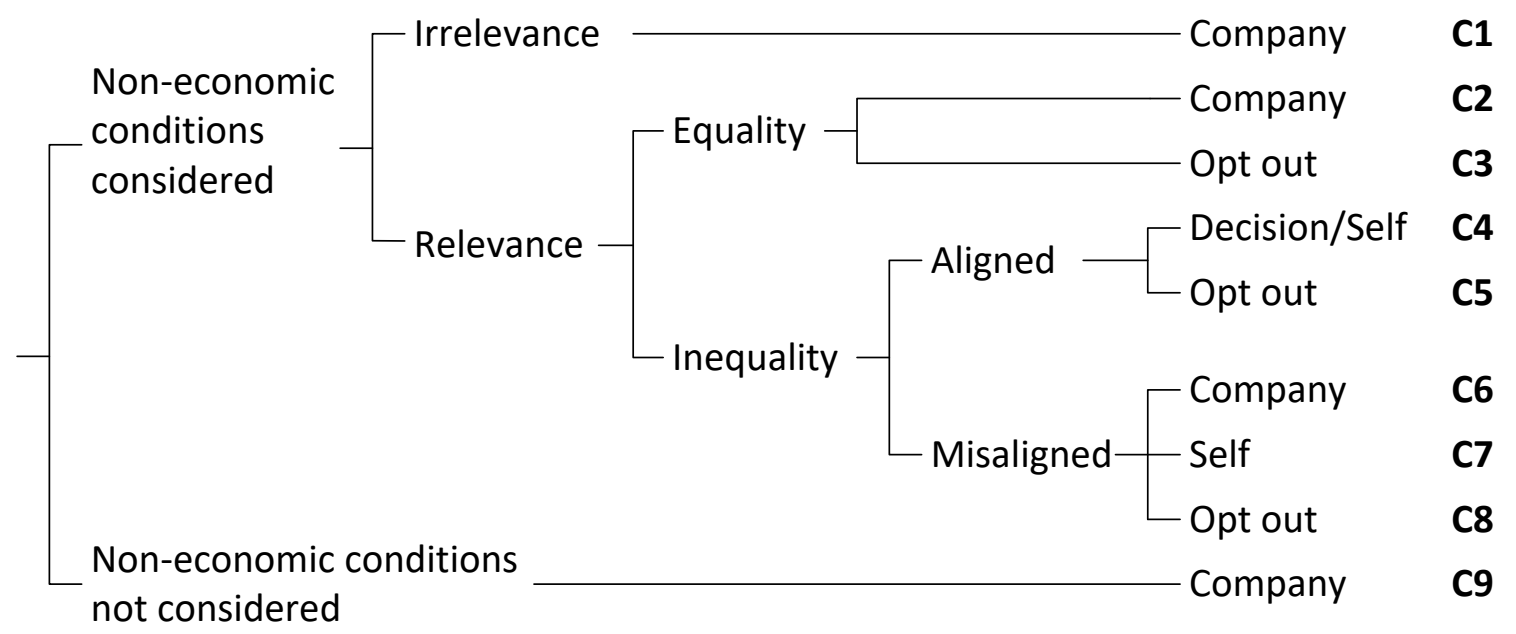

Figure 1. Taxonomy of types of solutions for the proposed type of assignment

Table 2. A characterization of solutions to the ethics problem

\begin{tabular}{|c|l|}
\hline Type & \multicolumn{1}{|c|}{ Learning impact } \\
\hline C1 & $\begin{array}{l}\text { This type of solution indicates awareness of ethics issues by the student, but the } \\
\text { problem is not adequately framed for the specific student, since it does not enable } \\
\text { them to navigate through the resolution of ethical conflicts. }\end{array}$ \\
\hline C2 & $\begin{array}{l}\text { This type of solution indicates awareness of ethics issues by the student. Students may } \\
\text { use two rationale to reach this solution. First, the student is unaware of the ability of } \\
\text { opt out of a decision. Second, the student is aware of the possibility to opt out, is } \\
\text { willing to opt out, but the consequences of going against the company are stronger } \\
\text { than the satisfaction of fulfilling his/her own preference system. The latter indicates } \\
\text { that the student understands how he/she resolves the conflict, but lacks mechanisms to } \\
\text { align his/her decision to his/her value system. }\end{array}$ \\
\hline C3 & $\begin{array}{l}\text { This type of solution indicates the student understands how to identify and resolve } \\
\text { ethical issues. }\end{array}$ \\
\hline C4 & $\begin{array}{l}\text { This case is similar to C2. } \\
\text { C5 }\end{array}$ This case is similar to C3. \\
\hline C6 & $\begin{array}{l}\text { This case indicates the student is aware of the possibility to opt out, is willing to opt } \\
\text { out, but the consequences of going against the company are stronger than the } \\
\text { satisfaction of fulfilling his/her own preference system. This also indicates that the } \\
\text { student understands how he/she resolves the conflict, but lacks mechanisms to align } \\
\text { his/her decision to his/her value system. }\end{array}$ \\
\hline C7 & $\begin{array}{l}\text { This type of solution indicates the student understands how to identify and resolve } \\
\text { ethical issues. }\end{array}$ \\
\hline C8 & $\begin{array}{l}\text { This type of solution indicates the student understands how to identify and resolve } \\
\text { ethical issues. }\end{array}$ \\
\hline C9 & $\begin{array}{l}\text { This type of solution indicates the student is unaware of the effect of ethics in } \\
\text { engineering work. }\end{array}$ \\
\hline
\end{tabular}


It should be noted that a student might opt to monetize all ethical implications to get to an objective decision that is free from ethical issues. However, all such efforts embed, necessarily, a subjective decision in the monetization effort, associated to beliefs and perceptions of impacts (Hazelrigg, 1998). Consequently, Figure 1 is valid for this case as well.

The work of the student does not however finalize with solving the problem. We believe it is key to perform a group activity in which various answers are shared among students to foster discussion. By exposing students to different types of answers and different viewpoints, students may deeply understand the dependency of engineering solutions to individual systems of preferences and ethical principles and values.

\section{Rubric}

Assessment is divided in three components:

1) The quality of the technical effort to solve the traditional part of the assignment.

2) The identification and awareness of the ethical conflict in the solution.

3) The quality of the resolution or discussion of the ethical conflict.

In this paper, we do not address the rubric for the first component, since it is independent of the ethical conflict.

We suggest that the second component, that is, the identification of the ethical conflict and showing an awareness for resolving it as part of the solution to the assignment, is used as an enabler or prerequisite to grading the rest of the assignment, including the first component. Essentially, no points would be given to a student who solves the assignment without identifying the ethical issue. We believe that this approach is key to successfully incorporating ethics into engineering education: it embeds the importance of ethics without altering a fair evaluation of technical competences.

The third component is graded as a function of how well the student incorporates ethical reasoning to inform the decision asked in the assignment. This is not measured as a function of the actual decision, since ethics are individual and there is no rightness or wrongness associated with it. Rather, we look at whether the student is able to use his/her own system of preferences to inform the decision at hand. This information can be collected in various ways. We identify some options below:

1) Incorporate explicit questions in the assignment where the student can justify their choice.

2) Add an optional scenario in the assignment, which does not require recalculations, but which changes the direction of the ethical conflict, that is, the ethical condition swaps. Then observe differences in student's answer.

3) Add an optional sensitivity analysis part to the assignment that finds the tipping point of the student's preference system.

We do not address in this paper the grade apportionment between the first and third components, because the specific balance depends on philosophical preferences of instructors and 
departments. We believe that as long as component 2 is used as a grade enabler, students will perceive the importance of ethical resolution skills in their profession.

\section{Intervention}

\section{Context}

The proposed approach to incorporate ethics in traditional optimization assignment has been developed for the senior level class Global Issues in Industrial Management at Virginia Tech. The course, an elective hosted by the Grado Department of Industrial and Systems Engineering, focuses on teaching how the practice of engineering changes in industrial settings. It addresses elements such as political and regulatory constraints (import and export tariff and quotas), foreign currencies, applicability of foreign legal systems, working in multicultural environments, resolution of emerging ethical issues, or the impact of international strategies to the practice of engineering.

The proposed approach was first implemented in Spring 2016. The course had 80 students; around 60 students majored in Industrial and Systems Engineering and the rest of the students majored in Packaging Design, Biological Systems Engineering, or Mechanical Engineering. Findings from this class have been used to inform some updates to the proposed approach, its proposed rubric, and the development of the intervention's protocol reported in this paper.

The intervention that is described in this paper took place in the Spring 2017 semester. The course has 86 students, from which 33 have participated in the intervention. One (1x) of the students majors in Mechanical Engineering, one (1x) majors in Electrical Engineering, and the rest major in Industrial and Systems Engineering.

\section{Protocol}

The intervention was structured in four phases, which are executed sequentially. They are described below.

\section{$\underline{\text { Phase 1. Traditional assignment }}$}

In this phase, students were given two traditional facility location problems as a pre-class assignment. Students completed the assignments in class, before initiating any instruction on ethics. Before coming to class, students will have read a conceptual chapter of a book on ethics in business. The chapter does not have any explicit example of how to embed ethics in engineering decision, but just theoretical concepts and some case studies from business. Students were asked to choose the facility that optimizes a given financial metric. The actual problems are given in Figure 2.

Because this class is taken mainly by junior and senior students, students are familiar with the type of assignment and it will be of low difficulty. Therefore, all students were expected to complete correctly all three problems with no difficulty. 
We expected the following behavior in all students:

1) They would choose the option with maximum financial metric.

2) They would not provide any indication or assumption that is linked to the choice.

\section{Problem 1.1}

In order to stay profitable, your company needs to incorporate a new material to its product. Two companies in two different countries are the only ones in the world that provide such material. You are assigned the task to recommend which company to subcontract.

Using the product from Company A will result in revenue of $\$ 100 \mathrm{M}$. The total cost for your company will be $\$ 43 \mathrm{M}$.

Using the product from Company B will result in revenue of $\$ 60 \mathrm{M}$. The total cost for your company will be $\$ 65 \mathrm{M}$.

Your company's objective is to maximize profit, trying to ensure a minimum of \$50M. Please, provide your recommendation for which company to subcontract.

\section{Problem 1.2}

In order to stay profitable, your company needs to incorporate a new material to its product. Two companies in two different countries are the only ones in the world that provide such material. You are assigned the task to recommend which company to subcontract.

Using the product from Company A will result in revenue of $\$ 100 \mathrm{M}$. The total cost for your company will be $\$ 35 \mathrm{M}$.

Using the product from Company B will result in revenue of $\$ 60 \mathrm{M}$. The total cost for your company will be $\$ 65 \mathrm{M}$.

Your company's objective is to maximize profit, trying to ensure a minimum of $\$ 50 \mathrm{M}$. Please, provide your recommendation for which company to subcontract.

Figure 2. Problems used in Phase 1

\section{Phase 2. Assignment with embedded ethics, before discussion}

In this phase, students were given three facility location problems that incorporate ethical issues as in-class assignment. Students were asked to choose the facility that optimizes a given financial metric. The actual problems are given in Figure 3. The assignment took place right after completion of the assignments in Phase 1, before any instruction on ethical issues has taken place.

The mathematical difficulty of the problems was similar to those problems used in Phase 1 . We expected the following behavior:

1) A majority of students would choose the option with maximum financial metric.

2) Some students would choose the option that aligns with their own values and principles.

3) Every student would choose an option. 


\section{Problem 2.1}

In order to stay profitable, your company needs to incorporate a new material to its product. Two companies in two different countries are the only ones in the world that provide such material. You are assigned the task to recommend which company to subcontract.

Using the product from Company A will result in revenue of $\$ 100 \mathrm{M}$. The total cost for your company will be $\$ 43 \mathrm{M}$. Company $\mathrm{A}$ is in a country where child labor is legal and children will be working in producing the material.

Using the product from Company B will result in revenue of $\$ 60 \mathrm{M}$. The total cost for your company will be $\$ 65 \mathrm{M}$. Company B is in a country that seconds international law. In order to lower total cost for your company below $\$ 40 \mathrm{M}$ you will need to fire 2,000 employees.

Your company's objective is to maximize profit, trying to ensure a minimum of \$20M. Please, provide your recommendation for which company to subcontract.

\section{Problem 2.2}

In order to stay profitable, your company needs to incorporate a new material to its product. Two companies in two different countries are the only ones in the world that provide such material. You are assigned the task to recommend which company to subcontract.

Using the product from Company A will result in revenue of $\$ 100 \mathrm{M}$. The total cost for your company will be $\$ 35 \mathrm{M}$. Company $\mathrm{A}$ is in a country that does not second environmental protection regulations. Producing the material implies high level of contaminants thrown to the ocean.

Using the product from Company B will result in revenue of $\$ 60 \mathrm{M}$. The total cost for your company will be $\$ 65 \mathrm{M}$. Company B is in a country that seconds international law. In order to lower total cost for your company below $\$ 40 \mathrm{M}$ you will need to fire 2,000 employees.

Your company's objective is to maximize profit, trying to ensure a minimum of $\$ 20 \mathrm{M}$. Please, provide your recommendation for which company to subcontract.

\section{Problem 2.3}

In order to stay profitable, your company needs to incorporate a new material to its product. Two companies in two different countries are the only ones in the world that provide such material. You are assigned the task to recommend which company to subcontract.

Using the product from Company A will result in revenue of $\$ 100 \mathrm{M}$. The total cost for your company will be $\$ 43 \mathrm{M}$. Company $\mathrm{A}$ is in a country that does not second environmental protection regulations. Producing the material implies high level of contaminants thrown to the ocean.

Using the product from Company B will result in revenue of $\$ 100 \mathrm{M}$. The total cost for your company will be $\$ 34 \mathrm{M}$. Company B is in a country where child labor is legal and children will be working in producing the material.

Your company's objective is to maximize profit, trying to ensure a minimum of \$20M. Please, provide your recommendation for which company to subcontract.

Figure 3. Problems used in Phase 2 


\section{Phase 3. Instruction}

This phase started in class right after submission of the assignment in Phase 2. Immediately following submission, students shared their answers. This was used as basis to discuss the topic class on ethics. The notions of decision-making, conflict between systems of preferences, and the ability to say 'no' were discussed.

\section{Phase 4. Assignment with embedded ethics, after discussion}

Eight weeks after instruction (Phase 4), students were given three new facility location problems that incorporated ethical issues as in-class assignments. Students were asked to choose the facility that optimizes a given financial metric. The actual problems are given in Figure 4. It was explicitly stated that the assignment did contribute to the course grade and that the students could answer anonymously.

The mathematical difficulty of the problems was similar to those problems used in Phases 1 and 2. We expected the following behavior:

1) Some students would choose the option with maximum financial metric, without considering ethical implications.

2) A majority of students would choose the option that aligns with their own values and principles.

3) Some students would not choose any option.

\section{Results}

The results of Phase 1 indicate that $100 \%$ of the students chose Company A in Problem 1.1 and Company A in Problem 1.2. In both cases, Company A is the one that maximizes profit. In fact, all students used profit as a justification for their choices. This confirms our initial expectation that students would just focus on optimizing the financial metric without considering other implications.

Results of Phase 2 are given in Table 3. In this case, students' responses were distributed primarily between Company A and Company B; consensus on the best solution was not achieved for any of the problems.

Table 3. Results of Phase 2

\begin{tabular}{|c|c|c|c|}
\hline Problem & Company A & Company B & Other \\
\hline 2.1 & 16 students (50\%) & 15 students (47\%) & 1 student (3\%) \\
\hline 2.2 & 5 students (16\%) & 26 students (81\%) & 1 student (3\%) \\
\hline 2.3 & 10 students (31\%) & 19 students (59\%) & 3 students (10\%) \\
\hline
\end{tabular}




\section{Problem 3.1}

In order to stay profitable, your company needs to incorporate a new cosmetic. Two companies in two different countries are the only ones in the world that provide such products. You are assigned the task to recommend which company to subcontract.

Using the product from Company A will result in revenue of $\$ 150 \mathrm{M}$. The total cost for your company will be $\$ 68 \mathrm{M}$. You know that Company A uses tests on monkeys and pigs to determine the quality of the product. Animals are caged and, while their health is controlled, secondary effects of the tests often results in problems related to skin, vision, and pulmonary activity.

Using the product from Company B will result in revenue of $\$ 90 \mathrm{M}$. The total cost for your company will be $\$ 95 \mathrm{M}$. Company B uses natural products with historic data on their safety towards human health. In order to lower total cost for your company below $\$ 40 \mathrm{M}$ you will need to fire 2,000 employees.

Your company's objective is to maximize profit, trying to ensure a minimum of \$20M. Please, provide your recommendation for which company to subcontract.

\section{Problem 3.2}

In order to stay profitable, your company needs to incorporate a new cosmetic. Two companies in two different countries are the only ones in the world that provide such products. You are assigned the task to recommend which company to subcontract.

Using the product from Company A will result in revenue of $\$ 140 \mathrm{M}$. The total cost for your company will be $\$ 58 \mathrm{M}$. You know that Company A does not tend to test their products comprehensively. Past data indicate that some of their products had to be recalled at some points because of effects on infant mortality, skin cancer, and fertility problems.

Using the product from Company B will result in revenue of $\$ 80 \mathrm{M}$. The total cost for your company will be $\$ 85 \mathrm{M}$. Company B uses natural products with historic data on their safety towards human health. In order to lower total cost for your company below $\$ 40 \mathrm{M}$ you will need to fire 2,000 employees.

Your company's objective is to maximize profit, trying to ensure a minimum of $\$ 20 \mathrm{M}$. Please, provide your recommendation for which company to subcontract.

\section{Problem 3.3}

In order to stay profitable, your company needs to incorporate a new cosmetic. Two companies in two different countries are the only ones in the world that provide such products. You are assigned the task to recommend which company to subcontract.

Using the product from Company A will result in revenue of $\$ 150 \mathrm{M}$. The total cost for your company will be $\$ 50 \mathrm{M}$. You know that Company A does not tend to test their products comprehensively. Past data indicate that some of their products had to be recalled at some points because of effects on infant mortality, skin cancer, and fertility problems.

Using the product from Company B will result in revenue of $\$ 150 \mathrm{M}$. The total cost for your company will be $\$ 68 \mathrm{M}$. You know that Company B uses tests on monkeys and pigs to determine the quality of the product. Animals are caged and, while their health is controlled, secondary effects of the tests often results in problems related to skin, vision, and pulmonary activity.

Your company's objective is to maximize profit, trying to ensure a minimum of $\$ 20 \mathrm{M}$. Please, provide your recommendation for which company to subcontract. 
In contrast with our expectations for this phase, results show that the majority of students did not try to maximize profit, but employed their own system of values and principles to inform their decision. First, answers to Problem 2.1 are evenly distributed, even though Company A (child labor) provides a better financial outcome. Second, answers to Problem 2.2 indicate a strong preference for Company B (employ layoff) over Company A (environmental pollution), even though Company A provides a better financial outcome. Third, answers to Problem 2.3 indicate a fair preference for Company B (child labor) over Company A (environmental pollution). Although in the last case Company B actually provides a better financial outcome, the results seem to indicate consistency between choice and individual values and principles.

Quantitative findings are supported by qualitative statements in the assignments made by students, such as "sometimes it is necessary to do the right thing", "the kids need to work in order to eat", "the irresponsible environmental protection policy affects the entire world", "child labor will help kids in the country stay fed and environmental policies affect the whole world", "can't imagine a company that practices child labor", "can't imagine running a company who does not care about the environment", or even more explicit "there is more moral issues running a company using child labor [than polluting the environment]". Qualitative data indicate that students use their individual scale of values for making the decision. Only one student addressed the need to elicit the preferences of their firm to inform the decision instead of their own system of personal values.

Qualitative data also indicates that morality is not the only decision factor students take, but they keep the financial target as part of their decision process. Examples include "also you don't need to invest as much", "has unethical aspects too but you make for less money", "it is legal and you make more profit", or "it will lower my total costs". In general, both the moral aspects and the financial aspects are raised concurrently by the students in their answers to the problems.

Quantitative data also shows that the majority of students embrace the action of making a choice, that is, they do not get away of the decision and only choose between the offered alternatives. Qualitative data supports this embracement with justifications such as "the lesser of two evils", "the greater good", or "if I had a choice I would choose neither, [but I have to choose one]". For Problems 2.1 and 2.2, only one student takes the position of not supporting any of the alternatives. Specifically, the student states that he/she needs more information to decide on Problem 2.1, such as specific children ages, safety of their work environment, or how easily employees will find another job. For Problem 2.2 the answer is more explicit and the student states that "I don't want to be a part of the decision". For Problem 2.3 two students take a similar position. One of the students also indicates that he/she needs more information before leaning towards one of the option. The other one is more explicit and indicates that "I would not recommend either company."

Phase 3 was devoted to instruction. Hence, it did not yield results.

Results of Phase 4 are given in Table 4. In this case, students' responses were also distributed primarily between Company A and Company B; consensus on the best solution was not achieved for any of the problems. 
In line with our expectations for this phase, results show that the majority of students did not try to maximize profit, but employed their own system of values and principles to inform their decision. First, answers to Problem 3.1 are evenly distributed, even though Company A (animal testing) provides a better financial outcome. Second, answers to Problem 3.2 indicate a strong preference for Company B (employee layoff) over Company A (human health risk), even though Company A provides a better financial outcome. Third, answers to Problem 3.3 indicate a fair preference for Company B (animal testing) over Company A (human health risk), although Company A provides better financial outcome. Furthermore, answers exhibit consistency of preferences in responses. Finally, some students opted out from the decision in all three problems.

Table 4. Results of Phase 4

\begin{tabular}{|c|c|c|c|}
\hline Problem & Company A & Company B & Other \\
\hline 3.1 & 15 students (47\%) & 15 students (47\%) & 2 students $(6 \%)$ \\
\hline 3.2 & 2 students $(6 \%)$ & 28 students $(88 \%)$ & 2 students $(6 \%)$ \\
\hline 3.3 & 6 students (19\%) & 21 students $(65 \%)$ & 5 students $(16 \%)$ \\
\hline
\end{tabular}

Quantitative findings are supported by qualitative statements in the assignments made by students. They are similar to those found in Phase 2 and include statements such as "I value my workers more than the animals", "I value the lives of my consumers more than having to lay off my workers", or "testing on animals is widely used". Qualitative data indicate that students use their individual scale of values for making the decision. In this case, a handful of students addressed the need to elicit the preferences of their firm to inform the decision instead of their own system of personal values. We suggest that this may result from some course material that was addressed during the time between Phase 2 and Phase 4.

In line with Phase 2, qualitative data also indicates that morality is not the only decision factor students take, but they keep the financial target as part of their decision process. In general, both the moral aspects and the financial aspects are raised concurrently by the students in their answers to the problems.

As in Phase 2, quantitative data shows that the majority of students embrace the action of making a choice. However, in line with the expectations for this phase, the number of students that decided to opt out of the decision increases with respect to Phase 2. Qualitative data in this regard includes statements such as "I cannot willingly allow my company to sell products that may harm people", "no matter the profit, I will never choose animal testing", or "both alternatives are unacceptable".

In order to factor out the assignments themselves, the assignment in Phase 4 was also provided to students in the same class who did not attend the session on Ethical issues and who did not do the assignments in Phases 1 and 2 and in instruction in Phase 3. Table 5 shows the results.

As quantitative data shows, every student took a decision between the two offered alternatives in all problems. As in Phase 2, qualitative data shows that some students were uncomfortable with the decision; nevertheless, they made a decision because they were not even aware that opting out was an acceptable engineering action. Examples of this include "Ideally, I wouldn't want to 
be in that business", "I believe both companies are participating in unethical practices", or "I would prefer neither, but..."

Table 5. Results of Phase 4 from students who did not participate in Phases 1, 2, and 3

\begin{tabular}{|c|c|c|c|}
\hline Problem & Company A & Company B & Other \\
\hline 3.1 & 11 students (55\%) & 9 students (45\%) & 0 students $(0 \%)$ \\
\hline 3.2 & 0 students $(0 \%)$ & 20 students $(100 \%)$ & 0 students $(0 \%)$ \\
\hline 3.3 & 1 student $(5 \%)$ & 19 students $(95 \%)$ & 0 students $(0 \%)$ \\
\hline
\end{tabular}

\section{Findings}

The intervention shows three interesting insights. First, absent of contextual information, students directly attack the problem to be solved and do not attempt to identify boundary conditions that would influence their recommendation. As shown in Phase 2, students' decisions are actually shaped by their own system of values and principles. Hence, a de-contextualized problem could lead to inconsistencies between the actual recommendation of an engineer and the recommendation the engineer would provide if they would know the context of the decision problem. Under these circumstances, we contend that the engineering community needs to examine the ethical issues arising from scenarios in which companies task engineers without providing the larger picture, the context of the problem.

Second, students impose their own individual system of preferences on a decision that incorporate elements that conflict with their own values and principles, as opposed to elicit the preferences of the corporation they work with. Although the latter is the normative approach in decision analysis, the former is a necessary attitude of the individual. Consequently, student behavior is inconsistent with the assumptions made around how engineering should perform. This reinforces the need for examining the ethical issues mentioned in the previous paragraph. The data also seems to indicate consistent use of personal preferences when making choices constrained by ethical issues.

Third, students have an inherent predisposition to make a choice from a closed set of alternatives, even if all alternatives conflict with their own system of values and principles. We hypothesize that such a behavior is constructed through accumulation of exposition to problems that require a definite answer out of a closed set of alternatives (or solutions). As discussed in the introductory section of this paper, we contend that such a behavior is the source of unfortunate outcomes and, consequently, must be rewired in students.

In addition, the results of Phase 4 seem to indicate that using the proposed assignments as instructional resources produce a change in student response to dealing with engineering problems that embed ethical conflicts (ref. Figure 5). Although the amount of students that consider opting out of the decision does not increase significantly between Phases 2 and 4, the difference between the students that participated in the learning activity (Phases 1, 2, and 3) and those who did not participate (Phase 4 only) is significant. It should be noted that it is not expected that every student opt out from the decisions, since conflicts will not emerge for every student due to their individual system of values and preferences. Therefore, we suggest that the differences between Phase 4 and Phase 2, and between Phase 4 students that participated in 
Phases 1, 2, and 3 and those who did not, provide sufficient indication of the value of embedding ethics in traditional industrial engineering problems to foster learning ethics. Hence, we suggest future work to explore the conditions under which assignments would maximize their effectiveness in teaching ethics.

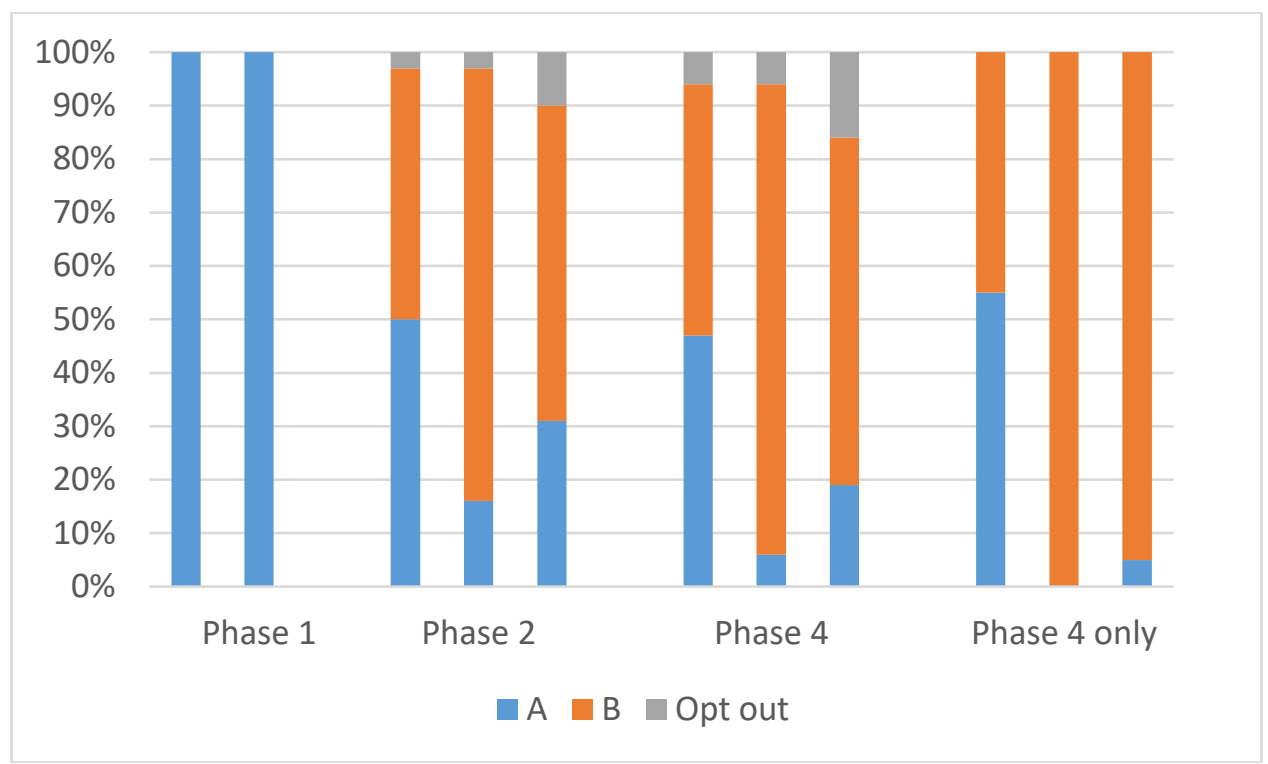

Figure 5. Comparison of results of Phases 1 (Pre-), 2 (Pre-), 4 (Post-), and 4 only (independent Pre-).

\section{Application of rubric}

Qualitative data in the assignments is used to apply the rubric previously presented.

Identification and awareness of the ethical conflict in the solution ( $\left.\mathbf{I}_{\mathbf{G}}\right)$ is demonstrated by students describing their thinking process leading to their choice. Examples include, as presented before, "sometimes it is necessary to do the right thing", "the kids need to work in order to eat", or "the irresponsible environmental protection policy affects the entire world". Some assignments declared a given answer, without justification, or simply indicating maximum profit as selection choice. We contend that these types of answers indicate unawareness of the emerging ethical conflict. However, we also recognize that this may result from a student exhibiting indifference between the various options. In order to identify this, we suggest combining problems that affect personal ethics with problems that force a conflict with engineering codes.

The quality of the resolution or discussion of the ethical conflict $\left(Q_{G}\right)$ is determined by the level of consistency of student's preferences between the various problems, the student's ability to define new scenarios or options that remove the conflict, and their ability to opt out of the decision. Examples include statements such as "reinvest some of the profit on ocean cleanup [activities]", "as long as children work in a safe environment", or "I would not recommend either company." 
Table 6 provides some examples of graded answers to Problems 2.1, 2.2, and 2.3. As can be seen, grading is independent of the stance that the student takes with respect to the ethical conflict.

Table 6. Sample graded answers to Problems 2.1, 2.2, and 2.3

\begin{tabular}{|c|c|c|c|c|}
\hline Student & Prob. & Solution & $\begin{array}{c}\mathbf{I}_{\mathbf{G}}\{\mathbf{0 , 1}\} \\
\mathbf{Q}_{\mathrm{G}}[\mathbf{0 , 1 0}] \\
\mathbf{G}\left(\mathbf{I}_{\mathbf{G}} \times \mathbf{Q}_{\mathbf{G}}\right)\end{array}$ & Comments \\
\hline \multirow[t]{3}{*}{1} & 2.1 & $\begin{array}{l}\text { "I recommend company A } \\
\text { because I value my } \\
\text { employees more than } \\
\text { foreign children and don't } \\
\text { want to have to fire them. } \\
\text { The profit will be } \$ 57 \mathrm{~m} . "\end{array}$ & $\begin{array}{c}\mathrm{I}_{\mathrm{G}}=1 \\
\mathrm{Q}_{\mathrm{G}}=10 \\
\mathrm{G}=10\end{array}$ & $\begin{array}{l}\text { The student identifies the ethical conflict and } \\
\text { justifies the selection by framing it with } \\
\text { respect to their individual system of values } \\
\text { and principles. }\end{array}$ \\
\hline & 2.2 & $\begin{array}{l}\text { "I would recommend } \\
\text { company A because again I } \\
\text { don’t want to fire my } \\
\text { employees. Since the profit } \\
\text { will be } \$ 65 \mathrm{~m} \text { I would use a } \\
\text { portion of the profit for } \\
\text { environmental work to } \\
\text { offset the pollutants } \\
\text { produced. }\end{array}$ & $\begin{array}{c}\mathrm{I}_{\mathrm{G}}=1 \\
\mathrm{Q}_{\mathrm{G}}=10 \\
\mathrm{G}=10\end{array}$ & $\begin{array}{l}\text { The student identifies the ethical conflict and } \\
\text { justifies the selection by framing it with } \\
\text { respect to their individual system of values } \\
\text { and principles. Furthermore, an alternative } \\
\text { scenario is created to align non-preferred } \\
\text { solution with }\end{array}$ \\
\hline & 2.3 & $\begin{array}{l}\text { "I would choose company B } \\
\text { because I will make the } \\
\text { most profit }(\$ 66 \mathrm{~m}) \text {, there } \\
\text { won't be significant } \\
\text { environmental impacts } \\
\text { compared to Company A, } \\
\text { and since child labor is } \\
\text { allowed in that country, it is } \\
\text { ok." }\end{array}$ & $\begin{array}{c}\mathrm{I}_{\mathrm{G}}=1 \\
\mathrm{Q}_{\mathrm{G}}=10 \\
\mathrm{G}=10\end{array}$ & $\begin{array}{l}\text { The student identifies the ethical conflict and } \\
\text { justifies the selection by framing it with } \\
\text { respect to their individual system of values } \\
\text { and principles. The answer is consistent with } \\
\text { previous answers: In Problem } 2.2 \text { the student } \\
\text { identified an alternative scenario to palliate } \\
\text { the effects of pollution, while in Problem } 2.1 \\
\text { the student does not attempt to palliate the } \\
\text { effects of child labor. This is indicative of a } \\
\text { preference of pollution over child labor, which } \\
\text { is exhibited in the answer to this problem. }\end{array}$ \\
\hline \multirow[t]{2}{*}{2} & 2.1 & "Company A" & $\begin{array}{l}\mathrm{I}_{\mathrm{G}}=0 \\
\mathrm{G}=0\end{array}$ & $\begin{array}{l}\text { Since the ethical conflict has not been } \\
\text { identified, the student receives } 0 \text { points. }\end{array}$ \\
\hline & 2.3 & $\begin{array}{l}\text { "Even though both issues } \\
\text { are unethical, human lives } \\
\text { are more important than } \\
\text { animals." }\end{array}$ & $\begin{array}{l}\mathrm{I}_{\mathrm{G}}=1 \\
\mathrm{Q}_{\mathrm{G}}=5 \\
\mathrm{G}=5\end{array}$ & $\begin{array}{l}\text { The student identifies the ethical conflict. } \\
\text { However, the answer indicates that the student } \\
\text { makes a choice even if considered unethical } \\
\text { within their own system of values and } \\
\text { preferences. Therefore, the quality of the } \\
\text { conflict resolution or discussion is considered } \\
\text { mediocre. }\end{array}$ \\
\hline
\end{tabular}

\section{Limitations}

This work has only addressed facility location problems with explicit declaration of ethical contexts. Further work is necessary to examine how students react to other types of problems and to ethical connotations that are not readily identifiable.

The various phases of the intervention have occur sequentially, with short time between them, and in the context of a given course. Therefore, although the qualitative data provides good insights about student thinking, it is not evident from the data if students act because of a learnt 
behavior or because of an understanding of how to identify and resolve ethical conflicts. Therefore, future work is necessary to examine student reactions to similar problems posed in other contexts and times, for example other courses.

\section{Conclusions and future work}

Industrial engineering is founded around optimization. Engineering curricula are therefore constructed around strong mathematical foundations. However, optimization in real life projects affect individual people and society. Therefore, understanding how ethical conflicts emerge, being able to identify them, and have the ability, courage, and power to resolve them is key for educating good industrial engineering professionals.

This paper has highlighted the integration of ethics into an existing, traditional industrial engineering undergraduate course at the senior level. In particular, we have shown how traditional optimization assignments can be reformulated to blend mathematics and ethics. Three primary benefits have been discussed. First, this enables teaching ethics without demanding additional credit hours in already packed curricula. Second, the student participates as an active learning, feeling the conflict and owning the responsibility of his/her decision, as opposed to passively understanding case studies. Third, students learn that opting out from a decision is a valid answer to an optimization problem: as engineers, we can say no.

In addition, we have suggested a rubric that considers the identification of ethical aspects an enabler for grading the assignment. This guarantees students understand the importance of ethics in engineering, without affecting fairness in evaluating their understanding of the associated technical concepts.

The intervention shows that, absent of context, students directly attack the problem to be solved and do not attempt to identify boundary conditions that would influence their recommendation. When context is provided, students impose their own individual system of preferences to resolve the emerging ethical conflicts. However, in all cases students have an inherent predisposition to make a choice from a closed set of alternatives, even if all alternatives conflict with their own system of values and principles, and they do not consider the option to get out of the decision. We contend that such a behavior is the source of unfortunate outcomes and, consequently, must be rewired in students. In fact, the results have shown that integrating ethics into traditional industrial engineering assignments can foster the necessary rewiring that enables students to consider opting out as a valid decision option when being exposed to alternatives that conflict with their individual system of values and principles.

Finally, we propose work in three directions. First, we plan to continue evolving traditional industrial engineering assignments and promoting their use among our colleagues. Second, we feel there is a need to experiment with different ways to approach rubric in order to guarantee fairness in the assessments of technical concepts and ethics issues, while simultaneously informing about the importance of ethics in the engineering profession. Third, we believe that this type of assignments can also facilitate better assessments ethics education in engineering programs. In particular, they can provide longitudinal evidence of a student's awareness of and competence in ethical aspects of the practice of engineering. 


\section{Bibliography}

ABET. (2007). Criteria for accrediting engineering programs: Effective evaluation during the 2008-2009 accreditation cycle. Baltimore, MD: Accreditation Board for Engineering and Technology.

Alenskis, B. A. (1997). Integrating Ethics Into An Engineering Technologu Course: An Interspersed Component Approach. Paper presented at the ASEE Annual Conference.

Clemen, R. T., \& Reilly, T. (2004). Making Hard Decisions with Decision Tools Suite Update Edition (1 ed.): Cengage Learning.

Colby, A., \& Sullivan, W. M. (2008). Ethics Teaching in Undergraduate Engineering Education. Journal of Engineering Education, 97(3), 327-338. doi:10.1002/j.2168-9830.2008.tb00982.x

Davis, M., \& Riley, K. (2008). Ethics Across the Graduate Engineering Curriculum: An Experiment in Teaching and Assessment. Teaching Ethics, 9(1), 25-42.

Fleischmann, S. T. (2004). Essential ethics - embedding ethics into an engineering curriculum. Science and Engineering Ethics, 10(2), 369-381. doi:10.1007/s11948-004-0033-5

Hazelrigg, G. A. (1998). A Framework for Decision-Based Engineering Design. Journal of Mechanical Design, 120(4), 653-658. doi:10.1115/1.2829328

Hazelrigg, G. A. (1999). An Axiomatic Framework for Engineering Design. Journal of Mechanical Design, 121(3), 342-347. doi:10.1115/1.2829466

Herkert, J. R. (1999). ABET's Engineering Criteria 2000 and Engineering Ethics: Where Do We Go From Here? Paper presented at the OEC International Conference on Ethics in Engineering and Science.

Herkert, J. R. (2002). Continuing and Emerging Issues in Engineering Ethics Education. The Bridge, 32.

Herkert, J. R., \& Viscomi, B. V. (1991). Introducing Professionalism and Ethics in Engineering Curriculum. Journal of Professional Issues in Engineering Education and Practice, 117(4), 383388.

Moore, J. (2011). The ethics education requirement: An examination of ethics education in engineering colleges. Public Knowledge Journal, 1(2). 